\title{
International Journal of Electroactive Materials
}

\author{
wWw.electroactmater.com
}

\section{Effect of cetyltrimethyl ammonium bromade surfactant concentration on the physical and photoelectrochemical property of $\mathrm{TiO}_{2}$ nanowire}

\author{
M.Y.A. Rahman ${ }^{1 *}$, A.A. Umar ${ }^{1 \#}$, L. $\operatorname{Roza}^{2}$, M.M. Salleh ${ }^{1}$ \\ ${ }^{1}$ Institute of Microengineering and Nanoelectronics (IMEN), Universiti Kebangsaan Malaysia, 43600, Bangi, Selangor, \\ Malaysia \\ ${ }^{2}$ College of Foundation and General Studies, Universiti Tenaga Nasional, 43009, Kajang, Selangor, Malaysia \\ *E-mail: *mohd.yusria@yahoo.com; " akrajas@ukm.my
}

\begin{abstract}
Cetyltrimethyl ammonium bromade (CTAB) surfactant was used to modify the morphology of $\mathrm{TiO}_{2}$ thin film nanowire prepared by a simple technique, namely, liquid phase deposition (LPD) during its growth process. In order to obtain various surface morphologies of $\mathrm{TiO}_{2}$ nanowires, the concentration of CTAB was varied from 7 to $10 \mathrm{mM}$. It was found that with the increase in the concentration of CTAB, the morphology of $\mathrm{TiO}_{2}$ nanowire in term of its diameter decreases due to the particles agglomeration grown on the surface. The $\mathrm{TiO}_{2}$ nanowires with various diameters were then utilized as photovoltaic materials in a photoelectrochemical cell. The highest performance of the cell in term of the shortcircuit current density, $J_{\mathrm{sc}}$ was $0.100 \mathrm{mAcm}{ }^{-2}$. This result was achieved from the $\mathrm{TiO}_{2}$ nanowire cell with the smallest grain size, $(6 \pm 2) \mathrm{nm}$. The $J_{\mathrm{sc}}$ of the cell increases with the increase in concentration of CTAB.
\end{abstract}

Keywords: Grain size; CTAB; Photo-electrochemical cell; Redox; $\mathrm{TiO}_{2}$

\section{Introduction}

Photoelectrochemical cell (PEC) is a photovoltaic device, which is formed by the interfacial contact of semiconductor with an electrolyte solution and counter electrode [1]. The ability to make a device from readily available material with simple fabrication process makes PEC is relatively cheap compared to other photovoltaic devices such as silicon and thin film solar cell. The role of metal oxide semiconductor layer in PEC is to generate free electrons upon light illumination [2].

Titanium dioxide $\left(\mathrm{TiO}_{2}\right)$ is the most commonly used photovoltaic material in PEC due to large band gap, high stability under extreme condition and low cost [2]. It is well known that the optical, electrical, and other properties of $\mathrm{TiO}_{2}$ are strongly influenced by the size and shape of particle. PEC based on porous and high surface area of $\mathrm{TiO}_{2}$ photovoltaic material will enhance charge collection and reduce combination reaction in electrolyte. Therefore, modified morphology of $\mathrm{TiO}_{2}$ film is highly demanded for improving the performance of PEC.

It has been reported that the morphology control of $\mathrm{TiO}_{2}$ nanostructures improved its electronic conductivity. The photovoltaic effect in PEC is determined by transport of electrons in redox reaction in electrolyte, compatible with grain size of $\mathrm{TiO}_{2}$ nanostructure [2]. The synthesis of $\mathrm{TiO}_{2}$ nanostructure with controllable morphology is essential to improve the PEC performance.

Various deposition techniques have been applied to prepare $\mathrm{TiO}_{2}$ nanostructures such as hydrothermal, anodic oxidation titanium, sol-gel method, chemical vapor deposition (CVD) and sputter coating [3-7]. Each technique produces unique morphologies such as rod, tube, wire, spherical, cubic and with different properties.
However, some techniques have limitations such as contamination by organic compound, harsh preparation condition or require high cost vacuum equipment. Liquid phase deposition (LPD) is an alternative simple technique for preparation of $\mathrm{TiO}_{2}$ thin film at low temperature via hydrolysis of metal-fluoro complex in the presence of boric acid [3].

LPD is a soft aqueous based chemical technique performed under atmospheric pressure at low temperature, which do not require special equipment [4]. In general, LPD was found to be a great process in obtaining anatase phase of $\mathrm{TiO}_{2}$ without the need of thermal treatment [5]. By LPD technique, relatively high area coatings have been successfully obtained on glass, conductive glass substrate and such condition is advantageous for device based on $\mathrm{TiO}_{2}$ [6]. LPD has been successful for depositing $\mathrm{TiO}_{2}$ thin film on the substrates and forms various morphology with controllable grain size and shape treated with surfactant, doped with organic or biological material [7-12].

Cetyltrimethyl ammonium bromade (CTAB) surfactant was extensively studied and used in growing $\mathrm{Zn}$ nanostructure [13]. Since $\mathrm{ZnO}$ is similar to $\mathrm{TiO}_{2}$ in some properties such as energy band gap and use in photovoltaic cell, CTAB is an appropriate surfactant in controlling the growth of $\mathrm{TiO}_{2}$ nanostructure in aqueous solution.

In this work, we have reported a novel soft technique to synthesize $\mathrm{TiO}_{2}$ nanowires with controllable morphology by varying the concentration of CTAB in the growth reaction. The influence of morphology in term of grain size of $\mathrm{TiO}_{2}$ nanowires on the performance of photoelectrochemical cell in term of short-circuit current density, $J_{\text {sc }}$, open-circuit voltage, $\left(V_{\text {oc }}\right)$ and fill factor $(F F)$ was investigated. 


\section{Experimental}

\subsection{Material}

Materials that were used for preparing $\mathrm{TiO}_{2}$ nanowires are ammonium hexaflourotitanate $\left(\mathrm{NH}_{4}\right)_{2} \mathrm{TiF}_{6}$ purchased from Sigma-Aldric, boric acid purchased from Wako Chemical. Cetyltrimethyl ammonium bromade (CTAB) surfactant was purchased from Acros Organics. These materials were used without further purification process. Indium Tin Oxide (ITO) coated glass with a sheet resistance of $9-22 \Omega / \mathrm{sq}$ was purchased from VinKarola instrument USA.

\subsection{Preparation of $\mathrm{TiO}_{2}$ nanowire}

ITO substrate was cleaned by wet cleaning of acetone, followed by 2-propanol in ultrasonic bath and dried under nitrogen flow. The substrate was immersed into a $10 \mathrm{ml}$ solution containing $0.1 \mathrm{M}\left(\mathrm{NH}_{4}\right)_{2} \mathrm{TiF}_{6}, 0.2 \mathrm{M} \mathrm{H}_{3} \mathrm{BO}_{3}$ in deionized water. The precursor solutions were mixed with 7 $\mathrm{mM}$ CTAB surfactant. The cleaned substrate was suspended vertically in the solution at $50{ }^{\circ} \mathrm{C}$ for 4 hours. The substrate was taken out and cleaned by de-ionized water. The sample was removed and washed with acetone to remove residual solution on glass side. The coated substrate was dried under nitrogen flow at room temperature. Finally, the sample was annealed at $400{ }^{\circ} \mathrm{C}$ for 1 hour to remove an organic binder and to enhance the interconnectivity of the particles.

These steps were repeated for preparing $\mathrm{TiO}_{2}$ nanowires treated with $\mathrm{CTAB}$ at other concentrations, namely, $8 \mathrm{mM}, 9 \mathrm{mM}$ and $10 \mathrm{mM}$. The structure and phase structure of the $\mathrm{TiO}_{2}$ samples were examined by xray diffraction (XRD) model Bruker D8 Advance measurements using $\mathrm{Cu} \mathrm{K}_{\alpha}$ radiation generated at energy of $40 \mathrm{kV}$ and current of $40 \mathrm{~mA}$, which emits a wavelength of $15.4 \mathrm{~nm}$. The XRD patterns of the samples were recorded in the range of $10^{\circ}$ to $60^{\circ}$ diffraction angle. The optical absorption of the samples was studied by UV-Vis spectrophotometer in the range 300-850 nm. Field emission-scanning electron microscopy (FE-SEM) Zeiss Supra 55VP FE SEM model was used to study the morphology in term of shape and particle size of the samples.

\subsection{Fabrication and performance study photoelectrochemical cell}

Platinum films as counter electrode were prepared by sputtering platinum pellet on ITO substrate. An electrolyte containing $0.5 \mathrm{M} \mathrm{LiI} / 0.05 \mathrm{M} \mathrm{I}_{2} / 0.5 \mathrm{M}$ tert-butylpyridine (TBP) in acetonitrile was used as redox couple. The electrolyte was sandwiched between the $\mathrm{TiO}_{2}$ nanoparticles film and the counter electrode. The cell was clamped in order to optimize the interfacial contact between the layers making up the cell. The performance study of the cell was carried out using an AM 1.5 simulated light with intensity of $100 \mathrm{mWcm}^{-2}$. The illuminated area of the cell is $0.8 \mathrm{~cm}^{2}$. The current-voltage curves of the cell in dark and under illumination were recorded by a Keithley high voltage source model 237 interfaced with personal computer. Each photovoltaic measurement was carried out five times using five $\mathrm{TiO}_{2}$ samples treated with CTAB surfactant at various concentrations, respectively.

\section{Results and discussion \\ 3.1 Characterization of $\mathrm{TiO}_{2}$ nanostructure}

Figure 1 shows the XRD patterns of the $\mathrm{TiO}_{2}$ samples treated with CTAB at various concentrations. For the $\mathrm{TiO}_{2}$ sample treated with $\mathrm{CTAB}$ with higher concentrations than $7 \mathrm{mM}$, the direction plane of the sample is dominant in (004) plane. For the samples treated with surfactant, all samples are purely in anatase phase because there are no new peaks noticeable in the spectra. There is no diffraction peaks of CTAB observed. This result revealed that the surfactant acts as a micelle template during the reaction which formed the porous structure of $\mathrm{TiO}_{2}$ with unique morphology.

The X-ray diffraction results also prove that annealing process removed the remaining surfactant on the surface substrate. The crystallize size calculated using Scherrer's formula for dominant peaks is found to vary from 20-25 $\mathrm{nm}$ in the presence of various concentration CTAB. Three diffraction peaks related to the $\mathrm{TiO}_{2}$ anatase phase, are observed at $25.26^{\circ}, 37.81^{\circ}$, and $55.03^{\circ}$ for all samples treated with CTAB. We found the extra peaks at $2 \theta=$ $30.9^{\circ}$, which imply the ITO phase in $\mathrm{TiO}_{2}$ sample treated with $8 \mathrm{mM}$ CTAB.

Figure 1 also shows the crystal phase of ITO. The presence of 2 peaks belonging to ITO substrate at $2 \theta=$ $30.57^{\circ}$ and $35.56^{\circ}$ indicates the $\mathrm{x}$-ray strikes the sample where the thickness and surface area of the sample are lower than that of other surface that are exposed to monochromatic x-ray. It is due to the thin layer of $\mathrm{TiO}_{2}$ samples which allows the $\mathrm{x}$-ray to penetrate through the $\mathrm{TiO}_{2}$ samples and reach ITO layer. This argument is supported by FE-SEM image observation which the surface morphology exhibits grass-like structure as shown in Figure 3. According to JCPDS (file no.21-1272), the peaks could be attributed to (101), (004) and (211), plane of anatase phase $\mathrm{TiO}_{2}$, correspondingly. Interestingly, there is no difference observed in the direction plane of the XRD spectra. Thus, it is confirmed that there is no structural change in the $\mathrm{TiO}_{2}$ samples.

Wide angle of XRD patterns shown in Figure 1 indicated that all $\mathrm{TiO}_{2}$ samples have high degree crystallinity with primary anatase phase. It is believed that the transformation of $\mathrm{TiO}_{2}$ from amorphous to crystalline was caused by annealing process with LPD technique. This result is in good agreement with that previously reported by Wang et al. and Zhang et al. [12, 13]. This result is correlated with the fact that the intensity of $\mathrm{TiO}_{2}$ sample treated with $10 \mathrm{mM}$ CTAB presents the highest intensity and broad peak at (004) direction plane followed with (101) plane. The intensity of (004) diffraction is much stronger than that of (101). 


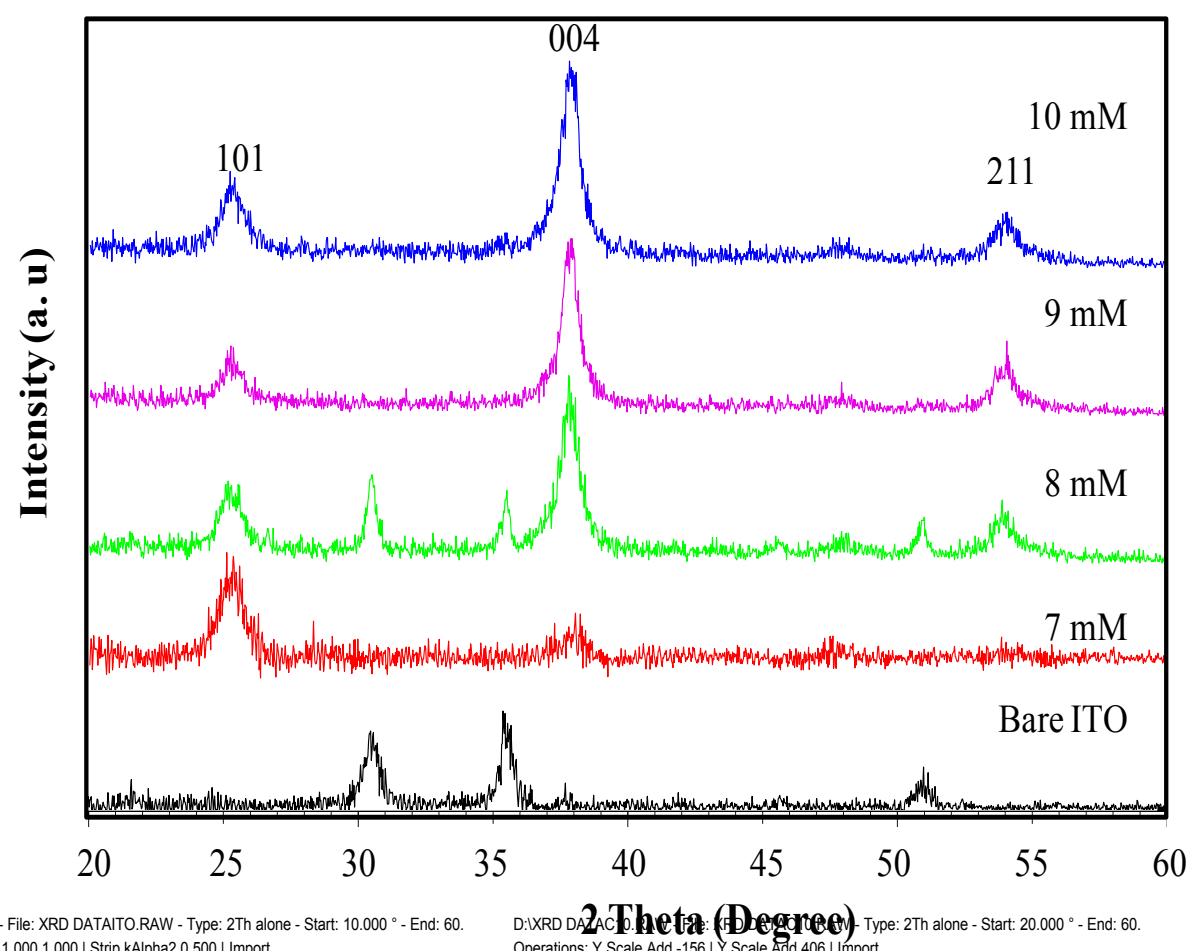

Figure 1: X-ray diffraction (XRD) patterns of $\mathrm{TiO}_{2}$ samples treated with various $\mathrm{CTAB}$ concentrations

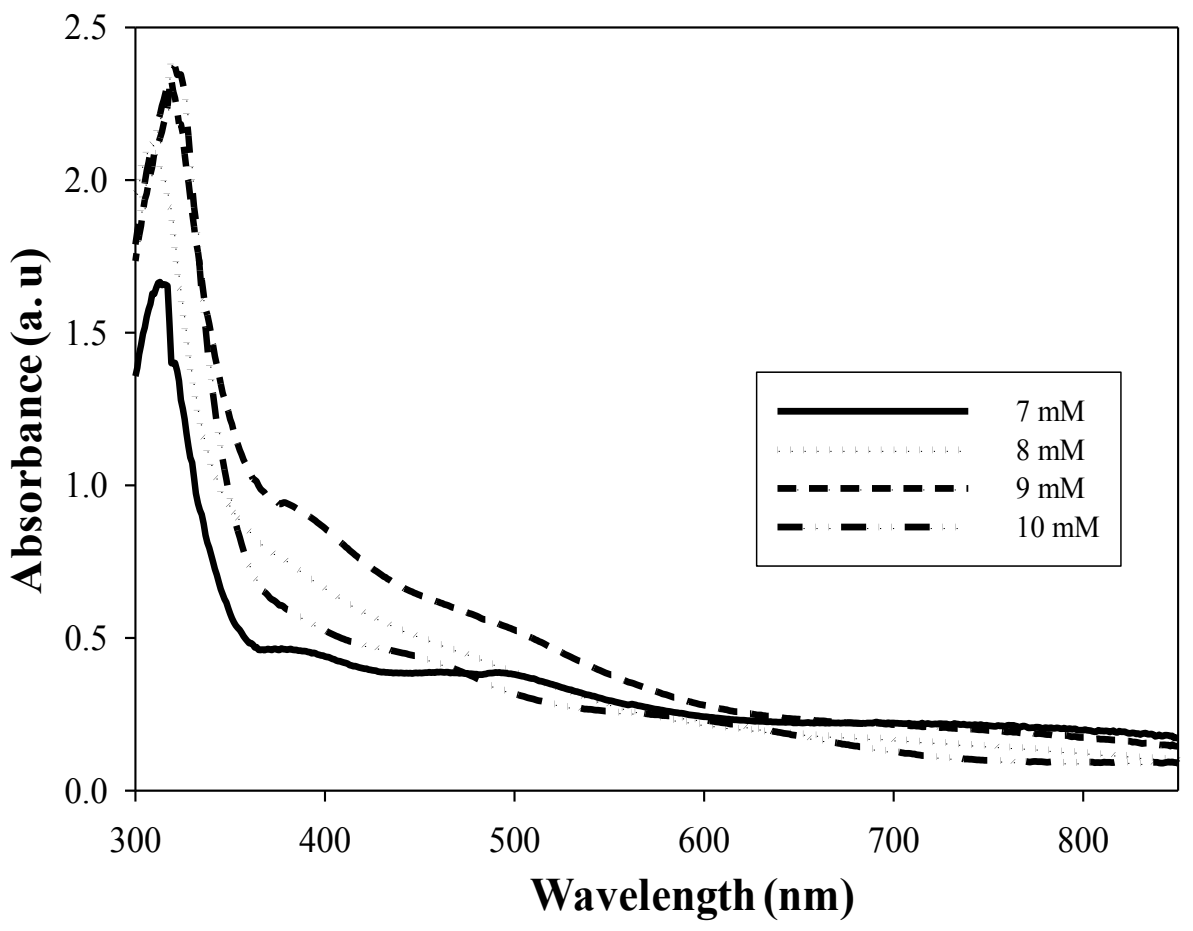

Figure 2: UV-Vis absorption spectra of $\mathrm{TiO}_{2}$ nanostructure with various concentration of CTAB 

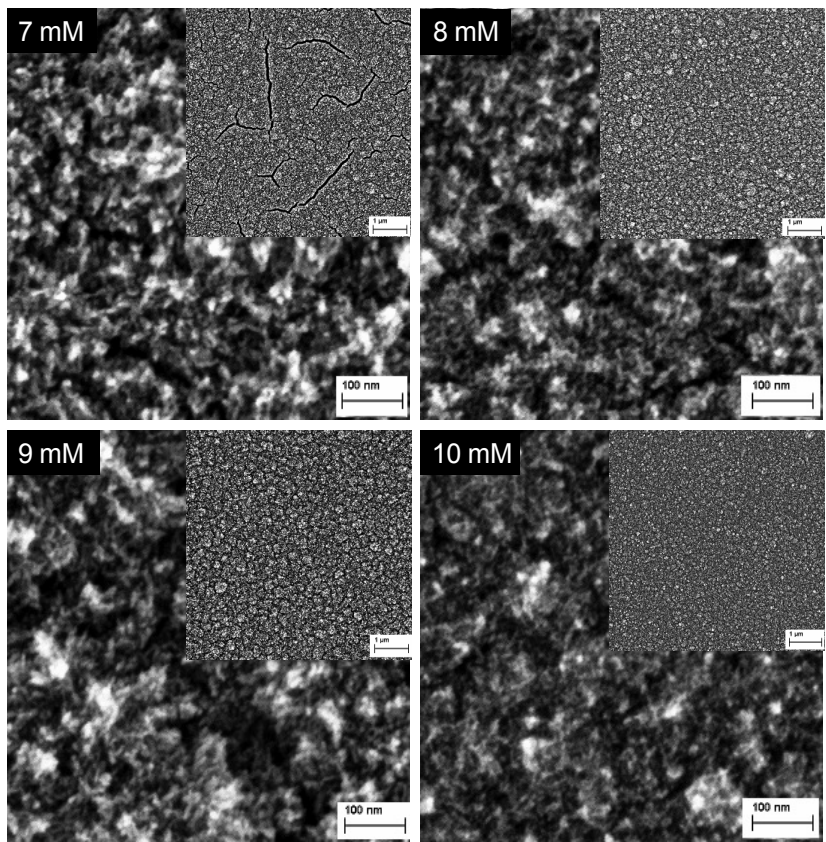

Figure 3: FESEM image of $\mathrm{TiO}_{2}$ nanowire treated with CTAB (a) $7 \mathrm{mM}$, (b) $8 \mathrm{mM}$, (c) $9 \mathrm{mM}$ and (d) $10 \mathrm{mM}$

The UV-Vis absorption spectra of $\mathrm{TiO}_{2}$ samples treated with various concentrations of CTAB are shown in Figure 2. The absorption of $\mathrm{TiO}_{2}$ sample prepared at various concentrations of CTAB show a prominent absorption near the blue region $(350-400 \mathrm{~nm})$. As evident from the figure, the absorption spectra of the $\mathrm{TiO}_{2}$ samples was increased by increasing the concentration of CTAB in the growth reaction. All $\mathrm{TiO}_{2}$ samples treated with CTAB show an absorption peak at UV wavelength at $380 \mathrm{~nm}$. Additionally, the absorption of $\mathrm{TiO}_{2}$ samples increased when the concentration of $\mathrm{CTAB}$ in the reaction is increased, which is attributed to the change in the grain size of particle. By increasing the concentration of CTAB during the reaction, the grain size of the $\mathrm{TiO}_{2}$ nanowire becomes smaller as shown in Figure 3. The concentration of CTAB influences the optical absorption of the $\mathrm{TiO}_{2}$ samples.

Figure 3 shows typical FESEM images of $\mathrm{TiO}_{2}$ nanowire treated with $\mathrm{CTAB}$ at various concentrations. The $\mathrm{TiO}_{2}$ nanowire treated with CTAB samples exhibit unique morphology as shown in Figure 3. Large-scale of grass-like $\mathrm{TiO}_{2}$ nanowire has successfully been obtained. The density and growth of $\mathrm{TiO}_{2}$ nanowire was significantly increased when the concentration of CTAB was increased. The thickness of $\mathrm{TiO}_{2}$ sample increases and the crack size on the surface became smaller with compact structure. However at different concentration of surfactant, the shape of $\mathrm{TiO}_{2}$ nanowire was almost similar with wirelike morphology. The grain size of $\mathrm{TiO}_{2}$ nanowire decreases at $10 \mathrm{mM}$ CTAB concentration. The smaller amount concentration of CTAB treatment the $\mathrm{TiO}_{2}$ film results in bigger crack as observed in $\mathrm{TiO}_{2}$ film. When the CTAB concentration was further increased, the cracks in $\mathrm{TiO}_{2}$ nanostructure particle disappear.
All images show morphology with closely packed particles, resulting in porous structure. The samples morphology is not homogenous since their grain sizes are not identical which is in the range $6-10 \mathrm{~nm}$ as illustrated in Table 1. On the basis of these experimental results, it can be concluded that the structural growth of $\mathrm{TiO}_{2}$ nanowire could be modified using treatment with different surfactant concentration. It should be noted that the amount of surfactant added into solution plays the key role in controlling the shape and morphology of $\mathrm{TiO}_{2}$ with compact and dense surface area. When the optimum conditions are obtained, the smaller grain size of $\mathrm{TiO}_{2}$ nanowire will be obtained. The film thickness increases linearly with the increase of concentration CTAB.

Figure 4 shows the cross-sectional viewing of $\mathrm{TiO}_{2}$ nanowire treated with $\mathrm{CTAB}$ surfactant at various concentrations. It can be clearly seen that the film are porous structured. The thickness of the $\mathrm{TiO}_{2}$ sample increases with the increase in CTAB concentration. It has been observed that crack structure formed on the surface does not effect until the bottom of sample. Such condition might be preferred for certain application, for example porous and smoother $\mathrm{TiO}_{2}$ nanowire would be improving the performance in PEC cell, and it is due to the porous structure which can absorb more ions from electrolytes. The image shows that the entire ITO surface as support layer of photoanode was fully covered with $\mathrm{TiO}_{2}$ nanostructure. This condition might be potential optimum surface area for redox activation in photoelectrochemical cell. As the morphology of the nanowire adopts the grass morphology, the diameters vary from about $10 \mathrm{~nm}$ at the bottom to ca. $8 \mathrm{~nm}$ at the nanowire tip.

Meanwhile, the thickness of the grass is ca about $8 \mathrm{~nm}$. The thickness of porous $\mathrm{TiO}_{2}$ sample is about $236 \mathrm{~nm}$ at 
the concentration $7 \mathrm{mM}$ of CTAB. The thickness increases with the concentration of CTAB. The top view FE-SEM image shows crack structure formed on the surface of the sample. However, the crack formation was not extended until the bottom of substrate. The agglomeration of the particle was first observed to disappear at the CTAB concentration $7 \mathrm{mM}$. The results indicated that $\mathrm{CTAB}$ surfactant was able to modify morphology of $\mathrm{TiO}_{2}$ sample and prevent the agglomeration of particles during growth reaction and annealing process.
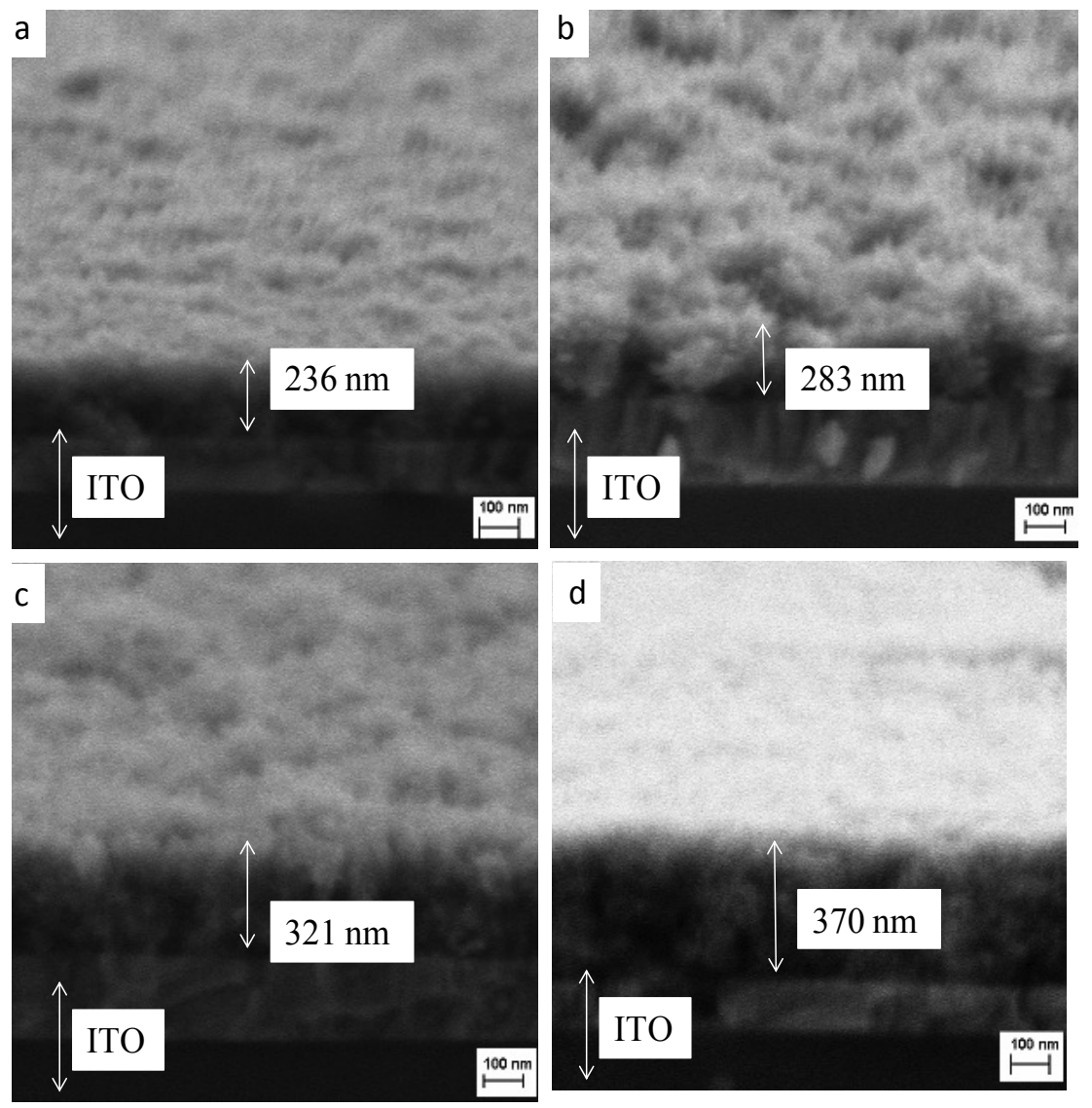

Figure 4: Cross-sectional viewing of $\mathrm{TiO}_{2}$ nanowire in the presence of CTAB at various concentrations (a) 7 $\mathrm{mM}$, (b) $8 \mathrm{mM}$, (c) $9 \mathrm{mM}$ and (d) $10 \mathrm{mM}$

\begin{tabular}{|c|c|c|c|c|}
\hline \multicolumn{5}{|c|}{$\begin{array}{l}\text { Table 1: } \\
\text { Diameter, thickness, UV wavelength absorption and estimated band gap of } \mathrm{TiO}_{2} \text { treated with various concentrations of } \\
\text { CTA }\end{array}$} \\
\hline CTAB & Average Diameter & Thickness & UV Wavelength & Estimated Band Gap (eV) \\
\hline $\begin{array}{c}\text { Concentration } \\
(\mathrm{mM})\end{array}$ & $(\mathrm{nm})$ & $(\mathrm{nm})$ & Absorption Peak (nm) & \\
\hline 7 & $10 \pm 2$ & 236 & 355 & 3.20 \\
\hline 8 & $8 \pm 2$ & 283 & 360 & 3.20 \\
\hline 9 & $8 \pm 2$ & 321 & 360 & 3.20 \\
\hline 10 & $6 \pm 2$ & 370 & 360 & 3.20 \\
\hline
\end{tabular}




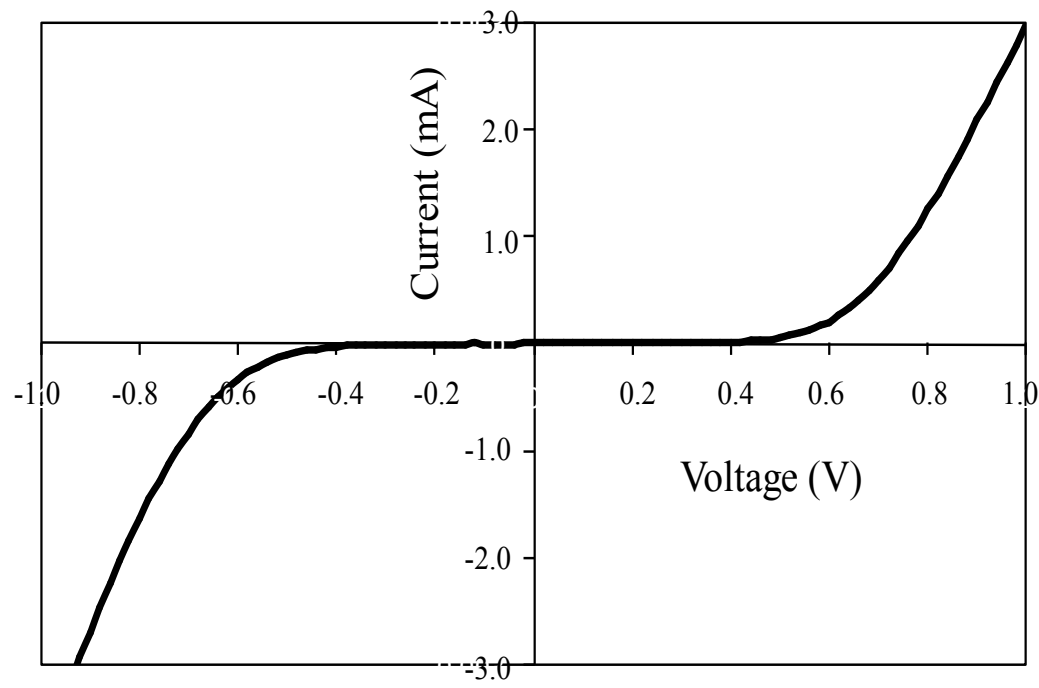

Figure 5: $I-V$ curve for the cell in dark

\section{Voltage (Volt)}

$\begin{array}{llllll}-0.05 & 0.05 & 0.15 & 0.25 & 0.35 & 0.45\end{array}$

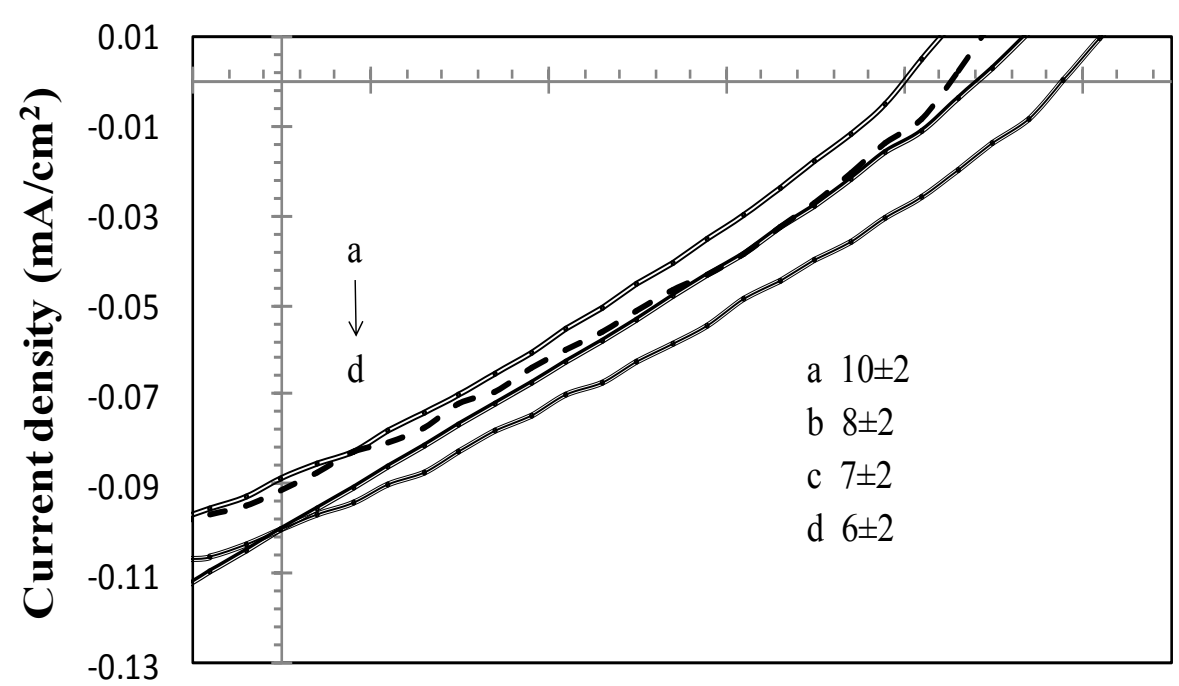

Figure 6: $J-V$ curves of the cell with various diameter of $\mathrm{TiO}_{2}$ nanowire treated with CTAB

Table 1 shows some parameters of $\mathrm{TiO}_{2}$ nanostructure analyzed from Figure 2 and Figure 3. According to the table, it was found that the $\mathrm{TiO}_{2}$ samples band gaps are larger than $3.0 \mathrm{eV}$ and shows high absorption in the UV wavelength. The varying concentration of CTAB was found to influence the morphology in term of grain size and optical absorption. The average grain size of the samples was estimated by taking the diameter of ten particles of $\mathrm{TiO}_{2}$ samples. The diameter of the particles was measured using the scale at the lower right corner of the SEM micrographs.
3.2 Performance of the photoelectrochemical cell of ITO/TiO $/$ /electrolyte/platinum

Figure 5 shows the current and voltage curve of the cell utilizing $\mathrm{TiO}_{2}$ nanostructure treated with CTAB in dark. It is clearly observed that the device does not show rectification, since the current in the forward bias is almost symmetric to that in the reverse bias [14]. Figure 6 shows the $J-V$ curves of the cell under illumination of 100 $\mathrm{mWcm}{ }^{-2}$ with various grain size of $\mathrm{TiO}_{2}$ nanowire treated with CTAB. It was found that the cell utilizing the $\mathrm{TiO}_{2}$ nanowire with the average diameter of $6 \pm 2 \mathrm{~nm}$ shows the highest current-density. 


\begin{tabular}{|c|c|c|c|}
\hline Average diameter of $\mathrm{TiO}_{2}(\mathrm{~nm})$ & $V_{o c}(\mathrm{~V})$ & $J_{s c}\left(\mathrm{~mA} / \mathrm{cm}^{2}\right)$ & $F F$ \\
\hline $10 \pm 2$ & 0.34 & 0.061 & 0.303 \\
\hline $8 \pm 2$ & 0.36 & 0.085 & 0.314 \\
\hline $8 \pm 2$ & 0.38 & 0.100 & 0.279 \\
\hline $6 \pm 2$ & 0.44 & 0.100 & 0.297 \\
\hline
\end{tabular}

Meanwhile, the cell utilizing the $\mathrm{TiO}_{2}$ nanowire with the average diameter of $10 \pm 2 \mathrm{~nm}$ shows the lowest current-density. The smaller diameter of the nanowire, the bigger current-density of the cell. The corresponding $J_{\mathrm{SC}}$, open-circuit voltage $\left(V_{\mathrm{OC}}\right)$ and $F F$ analyzed from Figure 6 are summarized in Table 2. It is observed that the smaller diameter of $\mathrm{TiO}_{2}$ nanowire, the higher $J_{s c}$ and $V_{o c}$ of the cell. However, this trend could not be seen in $F F$. The highest $J_{\mathrm{sc}}$ was achieved with the cell assembled with the nanowire-like $\mathrm{TiO}_{2}$ with the smallest average diameter of $6 \pm 2 \mathrm{~nm}$. The smallest diameter of the $\mathrm{TiO}_{2}$ nanowire provides the best interfacial contact at the interface of $\mathrm{TiO}_{2}$ layer and the electrolyte, causing more holes to be captured by iodide ions in the electrolyte [15]. This will lead to faster rate of reduction, oxidation and excitation of electron-hole pairs in $\mathrm{TiO}_{2}$, resulting in enhancement of photovoltaic performance of the cell.

The porosity of $\mathrm{TiO}_{2}$ nanostructure is another important factor that determines the diffusion transport of ions for improvement of performance of the cell [1]. High density $\mathrm{TiO}_{2}$ with compact nanowire without any crack and cavities will enhance the contact surface area between $\mathrm{TiO}_{2}$ nanostructure and ITO providing more electrons pathway for photoelectron regeneration, which facilitate transfer of electrons and improve the performance of the cell $[16,17]$. It also acts as a blocking layer to prevent the charge recombination between ITO layer and liquid electrolyte $[15,18]$. The anatase phase of $\mathrm{TiO}_{2}$ exists primarily with treated with CTAB, influences the performance of the cell $[19,20]$. Enhancement of performance of the cell can be achieved by utilizing $\mathrm{TiO}_{2}$ anatase phase, as it is the most efficient phase of $\mathrm{TiO}_{2}$ according to the literature $[21,22]$.

\section{Conclusion}

CTAB treated $\mathrm{TiO}_{2}$ nanowire was successfully prepared by a simple technique, liquid phase deposition (LPD). It was found that with the increase in the concentration of CTAB, the morphology of $\mathrm{TiO}_{2}$ nanostructure in term of its grain size decreases due to the $\mathrm{TiO}_{2}$ particles agglomeration grown on ITO surface. The $\mathrm{TiO}_{2}$ nanostructures with various grain sizes were utilized as photovoltaic materials in photoelectrochemical cell. It was found that the performance of the cell in term of the short-circuit current density, $J_{\mathrm{sc}}$ increases with the decrease in the grain size of $\mathrm{TiO}_{2}$ nanostructure. The highest $J_{\text {sc }}$ of $0.100 \mathrm{mAcm}^{-2}$ was achieved at the $\mathrm{TiO}_{2}$ nanowire cell with the smallest grain size, $(6 \pm 2) \mathrm{nm}$. The cell utilizing the $\mathrm{TiO}_{2}$ nanowires with the smallest grain size demonstrates the best interfacial contact at $\mathrm{TiO}_{2} /$ electrolyte containing iodide/triiodide redox couple, optimizing the redox reaction at this interface.

\section{Acknowledgment}

This work was supported by The Ministry of higher Education of Malaysia under research grant FRGS 011010118 .

\section{References}

1. B. O’Regan, M. Grätzel, Nature 353 (1991) 737740 .

2. M. Grätzel, J. Photochem. Photobiol. C: Photochem. Rev. 4 (2003) 145-153.

3. S. Deki, Y. Aoi, O. Hiroi, A. Kajinami, Chem. Lett. 6 (1996) 433-434.

4. L. Li, M. Mizuhata, S. Deki, Appl. Surf. Sci. 239 (2005) 292-301.

5. Y. Masuda, M. Bekki, S. Sonezaki, T. Ohji, K. Kato, Thin Solid Films 518 (2009) 845-849.

6. Y. Ding, C. Yang, L. Zhu, J. Zhang, J. Hazard Mater. 175 (2010) 96-103.

7. D. Gutiérrez-Tauste, X. Domènech, C. Domingo, J.A. Ayllón, Thin Solid Films 516 (2008) 38313835 .

8. M. Tatemichi, M. Sakamoto, M. Mizuhata, S. Deki, T. Takeuchi, J. Am. Chem. Soc. 129 (2007) 1090610910

9. J. Zhang, Y. Zheng, G. Jiang, C. Yang, M. Oyama, Electrochem. Commun. 10 (2008) 1038-1040.

10. J. Zhang, Q. Ding, R. Wang, J. Gong, C. Yang, Electrochim. Acta 55 (2010) 3614-3620.

11. G. Jiang, H. Tang, L. Zhu, J. Zhang, B. Lu, Sens. Actuator B-Chem. 138 (2009) 607-612.

12. X.P. Wang, Y. Yu, X.F. Hu, L. Gao, Thin Solid Films 371 (201) 148-152.

13. J. Zhang, C. Yang, G. Chang, H. Zhu, M. Oyama, Mater. Chem. Phys. 88 (2004) 398-403.

14. M.Y.A. Rahman, M.M. Salleh, I.A. Talib, M. Yahaya, Curr. Appl. Phys. 5 (2005) 599-602.

15. H. Xu, X. Tao, D.T. Wang, Y.Z. Zheng, J.F. Chen, Electrochim. Acta 55 (2010) 2280-2285.

16. P. Wang, S.M. Zakeeruddin, J.E. Moser, M.K. Nazeeruddin, T. Sekiguchi, M. Gratzel, Nat. Mater. 2 (2003) 402-407. 
17. S. Ito, T.N. Murakami, P. Comte, P. Liska, C. Gratzel, M.K. Nazeeruddin, M. Gratzel, Thin Solid Films 516 (2008) 4613-4619.

18. N. Papageorgiou, W.F. Maier, M. Gratzel, J. Electrochem. Soc. 144 (1997) 876-884.

19. V. Dhas, S. Muduli, S. Agarkar, A. Rana, B. Hannoyer, R. Banerjee, S. Ogale, Sol. Energy 85 (2011) 1213-1219.

20. M. Durr, A. Schmid, M. Obermaier, S. Rosselli, A. Yasuda, G. Nelles, Nat. Mater. 4 (2005) 607-611.
21. S.Y. Choi, M. Mamak, N. Coombs, N. Chopra, G.A. Ozin, Nano Lett. 4 (2004) 607-611.

22. Y. Masuda, M. Bekki, S. Sonezaki, T. Ohji, K. Kato, Solid State Ionics 172 (2009) 283-288.

Received: April 21, 2013 / Accepted: May 13, 2013

(C) 2013 by Rahman et al.; Licensee Electroactive Materials Society 